\title{
PEMBUKTIAN SIFAT RUANG BANACH PADA $D(K)$
}

\author{
Malahayati \\ Program Studi Matematika Fakultas Sains dan Teknologi UIN Sunan Kalijaga \\ malahayati_01@yahoo.co.id
}

\begin{abstract}
In this paper we study class of all functions which are differences of bounded semicontinuous functions on a separable metric space $K$ denoted by $D(K)$. Haydon, Odell and Rosenthal (1991) proved that $D(K)$ is a Banach space by using the series criterion for completeness. In this paper we prove the statement in a different way.
\end{abstract}

Keywords: Banach Space, Semicontinuous function, The Class $D(K)$.

\begin{abstract}
ABSTRAK. Di dalam paper ini dipelajari kelas semua fungsi yang merupakan selisih fungsi-fungsi semikontinu terbatas pada ruang metrik separabel $K$ yang dinotasikan dengan $D(K)$. Haydon, Odell dan Rosenthal (1991) membuktikan bahwa $D(K)$ merupakan ruang Banach dengan menggunakan kriteria deret untuk kelengkapan. Di dalam paper ini hal tersebut dibuktikan dengan cara yang berbeda.
\end{abstract}

Kata Kunci: Ruang Banach, Fungsi Semikontinu, Kelas D(K).

\section{PENDAHULUAN}

Himpunan semua fungsi Baire kelas satu yang terbatas pada $K$ ditulis $B_{1}(K)$, dengan $K$ sembarang ruang metrik separabel. Salah satu kelas bagian terpenting dari $B_{1}(K)$ adalah $D(K)$, yang menotasikan kelas semua fungsi pada $K$ yang merupakan selisih fungsi-fungsi semikontinu terbatas pada $K$. Kelas $D(K)$ pertama kali dikenalkan oleh A.S Kechris dan Louveau pada tahun 1990.

Sejalan dengan kemajuan sains dan teknologi, kajian tentang $D(K)$ juga mengalami perkembangan sehingga muncul beberapa pengertian tentang $D(K)$ dan norma pada $D(K)$, seperti yang ditulis oleh Haydon, Odell, Rosenthal (1991) dan Rosenthal (1994) serta Farmaki (1996).

Kelas fungsi $D(K)$ memiliki peranan penting dalam cabang matematika diantaranya analisis fungsional, khususnya dalam pengaplikasian teori ruang Banach. 
Hasil temuan Haydon, Odell, Rosenthal dan Farmaki tersebut memberikan inisiatif untuk mempelajari lebih dalam tentang kelas fungsi $D(K)$. Lebih lanjut, karena belum ada pembuktian secara detail tentang sifat ruang Banach pada $D(K)$ maka dalam paper ini akan diberikan pembuktian sifat tersebut.

Sebelumnya diberikan terlebih dahulu definisi fungsi semikontinu yang akan digunakan dalam pendefinisian kelas fungsi $D(K)$. Fungsi - fungsi yang dibicarakan bernilai real dan didefinisikan pada $E$, dengan $E$ himpunan bagian dari sebarang ruang metrik.

Definisi 1.1 Diberikan fungsi f yang didefinisikan pada $E$ dan $x_{0} \in E$.

1) Limit atas (upper limit) fungsi $f$ untuk $x$ mendekati $x_{0}$ ditulis dengan $\overline{\lim }_{x \rightarrow x_{0}} f(x)$ dan didefinisikan :

$$
\varlimsup_{x \rightarrow x_{0}} f(x)=\inf \left\{M_{\varepsilon}\left(f, x_{0}\right): \varepsilon>0\right\},
$$

dengan $M_{\varepsilon}\left(f, x_{0}\right)=\sup \left\{f(x): x \in N_{\varepsilon}\left(x_{0}\right) \cap E\right\}$.

2) Limit bawah (lower limit) fungsi $f$ ketika $x$ mendekati $x_{0}$ ditulis dengan $\underline{\lim }_{x \rightarrow x_{0}} f(x)$ dan didefinisikan :

$$
\underline{\lim }_{x \rightarrow x_{0}} f(x)=\sup \left\{m_{\varepsilon}\left(f, x_{0}\right): \varepsilon>0\right\},
$$

dengan $m_{\varepsilon}\left(f, x_{0}\right)=\inf \left\{f(x): x \in N_{\varepsilon}\left(x_{0}\right) \cap E\right\}$.

Definisi 1.2 Diberikan fungsi $f$ yang didefinisikan pada $E$ dan $x_{0} \in E$.

1) Fungsi $f$ dikatakan semikontinu atas (upper semicontinuous) di $x_{0}$

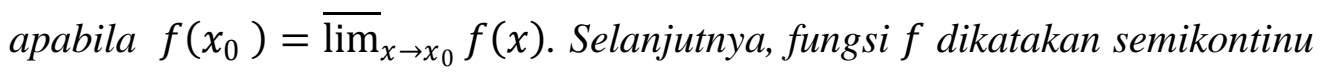
atas pada $E$ apabila fungsi $f$ semikontinu atas disetiap $x \in E$.

2) Fungsi $f$ dikatakan semikontinu bawah (lower semicontinuous) di $x_{0}$ apabila $f\left(x_{0}\right)=\lim _{x \rightarrow x_{0}} f(x)$. Selanjutnya, fungsi $f$ dikatakan semikontinu bawah pada $E$ apabila fungsi $f$ semikontinu bawah disetiap $x \in E$.

3) Fungsi yang semikontinu atas atau semikontinu bawah dinamakan fungsi semikontinu. 


\section{HASIL DAN PEMBAHASAN}

Pada bagian ini akan dibahas pengertian dan beberapa sifat pada $D(K)$ dilanjutkan dengan membuktikan sifat ruang Banach pada $D(K)$. Fungsi - fungsi yang dibicarakan bernilai real dan didefinisikan pada $K$, dengan $K$ sebarang ruang metrik separabel kecuali disebutkan lain. Selain itu, himpunan semua fungsi - fungsi kontinu pada $K$ dinotasikan dengan $C(K)$.

Fungsi $f$ dikatakan anggota $D(K)$ jika terdapat fungsi - fungsi semikontinu terbatas $u$ dan $v$ pada $K$ sehingga $f=u-v$.

Di dalam membahas sifat-sifat $D(K)$, pemakaian definisi $D(K)$ secara langsung cukup menyulitkan. Oleh karena itu, diperlukan suatu hasil yang lebih memudahkan dalam pembahasan yang dimaksud. Hal ini telah ditulis oleh Farmaki (1996) yang tertuang dalam lemma-lemma berikut ini.

Lemma 2.1 Fungsi $f \in D(K)$ jika dan hanya jika terdapat fungsi-fungsi semikontinu bawah terbatas $u$ dan $v$ pada $K$, sehingga $f=u-v$.

Lemma 2.2 Fungsi $f \in D(K)$ jika dan hanya jika terdapat fungsi - fungsi semikontinu bawah terbatas $u, v \geq 0$ pada $K$, sehingga $f=u-v$.

Untuk sembarang ruang metrik separabel $K$, jelas bahwa $D(K)$ merupakan ruang linear. Selanjutnya, diberikan definisi fungsi $\|.\|_{D}$, yang akan sangat bermanfaat dalam pembuktian berikutnya.

Definisi 2.3 Diberikan ruang metrik separabel $K$, didefinisikan fungsi $\|.\|_{D}: D(K) \rightarrow \boldsymbol{R}$, dengan

$$
\begin{gathered}
\|f\|_{D}=\inf \left\{\|u+v\|_{\infty}: f=u-v, \text { dengan } u, v \geq 0 \text { fungsi }-\right. \text { fungsi } \\
\text { semikontinu bawah terbatas pada } K\},
\end{gathered}
$$

untuk setiap $f \in D(K)$.

Selanjutnya akan dibuktikan bahwa $D(K)$ merupakan ruang bernorma terhadap fungsi $\|.\|_{D}$. Terlebih dahulu diberikan beberapa lemma yang akan digunakan dalam pembuktian. 
Lemma 2.4 Jika $f \in D(K)$ maka $\|f\|_{\infty} \leq\|f\|_{D}$.

Lemma 2.5 Jika $f \in D(K)$ dan $\alpha \in \boldsymbol{R}$ maka berlaku

$\left\{\|\alpha(u+v)\|_{\infty}: \alpha f=\alpha u-\alpha v\right.$, dengan $u, v \geq 0$ fungsi - fungsi semikontinu bawah terbatas pada $K\}=\left\{\|h+g\|_{\infty}: \alpha f=h-g\right.$, dengan $h, g \geq 0$ fungsi fungsi semikontinu bawah terbatas pada $K$ \}.

Seperti yang telah disebutkan sebelumnya, dengan menggunakan Lemma 2.4 dan Lemma 2.5, dibuktikan bahwa fungsi $\|.\|_{D}$ adalah norma pada $D(K)$.

Teorema 2.6 Fungsi $\|.\|_{D}$ adalah norma pada $D(K)$.

\section{Bukti :}

(N1). Diambil sembarang $f \in D(K)$. Karena

$\|f\|_{D}=\inf \left\{\|u+v\|_{\infty}: f=u-v\right.$, dengan $u, v \geq 0$ fungsi - fungsi

semikontinu bawah terbatas pada $K\}$,

maka diperoleh $\|f\|_{D} \geq 0$. Selanjutnya, jika $\|f\|_{D}=0$ maka menurut Lemma 2.4 diperoleh $\|f\|_{\infty}=0$. Oleh karena itu, $f(x)=0$ untuk setiap $x \in K$, dengan kata lain $f=\mathbf{0}$. Sebaliknya, jika $f=\mathbf{0}$ maka terdapat fungsi-fungsi semikontinu bawah terbatas $u=\mathbf{0}$ dan $v=\mathbf{0}$, sehingga $f=u-v=\mathbf{0}$, akibatnya diperoleh

$$
\begin{gathered}
\|f\|_{D}=\inf \left\{\|u+v\|_{\infty}: f=u-v, \text { dengan } u, v \geq 0 \text { fungsi }-\right. \text { fungsi } \\
\text { semikontinu bawah terbatas pada } K\}=0 .
\end{gathered}
$$

(N2). Diambil sembarang $f \in D(K)$ dan $\alpha \in \boldsymbol{R}$. Berdasarkan Lemma 2.5, diperoleh

$|\alpha| .\|f\|_{D}=|\alpha| \inf \left\{\|u+v\|_{\infty}: f=u-v\right.$, dengan $u, v \geq 0$ fungsi -

fungsi semikontinu bawah terbatas pada $K$ \}

$$
=\inf \left\{|\alpha|\|u+v\|_{\infty}: f=u-v \text {, dengan } u, v \geq 0 \text { fungsi }-\right.
$$

fungsi semikontinu bawah terbatas pada $K$ \}

$=\inf \left\{\|\alpha(u+v)\|_{\infty}: \alpha f=\alpha u-\alpha v\right.$, dengan $u, v \geq 0$ fungsi -

fungsi semikontinu bawah terbatas pada $K\}$

$=\inf \left\{\|h+g\|_{\infty}: \alpha f=h-g\right.$ dengan $h, g \geq 0$ fungsi -

fungsi semikontinu bawah terbatas pada $K$ \}

$=\|\alpha f\|_{D}$. 
(N3). Diambil sembarang $f, g \in D(K)$ dan $\varepsilon>0$ sembarang, maka terdapat fungsi - fungsi semikontinu bawah terbatas $u, v, s, t \geq 0$ dengan $f=u-v$ dan $g=s-t$, sehingga berlaku

$$
\|u+v\|_{\infty}<\|f\|_{D}+\frac{\varepsilon}{2} \text { dan }\|s+t\|_{\infty}<\|g\|_{D}+\frac{\varepsilon}{2} .
$$

Oleh karena itu, diperoleh

$$
\begin{aligned}
\|f\|_{D}+\|g\|_{D}+\varepsilon & >\|u+v\|_{\infty}+\|s+t\|_{\infty} \\
& \geq\|(u+v)+(s+t)\|_{\infty} \\
& =\|(u+s)+(v+t)\|_{\infty} \\
& \geq\|f+g\|_{D} .
\end{aligned}
$$

Karena berlaku untuk $\varepsilon>0$ sembarang, maka diperoleh

$$
\|f+g\|_{D} \leq\|f\|_{D}+\|g\|_{D} .
$$

Berdasarkan (N1), (N2), dan (N3), maka terbukti bahwa fungsi $\|.\|_{D}$ adalah norma pada $D(K)$.

Pengertian norma pada $D(K)$ dapat juga disajikan lain, yang tertuang dalam teorema-teorema berikut ini.

Teorema 2.7 Fungsi $f \in D(K)$ jika dan hanya jika terdapat barisan $\left\{f_{n}\right\}$ di $C(K)$ dan $\sup _{x \in K} \sum_{n}\left|f_{n}(x)\right|<\infty \quad$ sehingga $\sum_{n} f_{n}=f$ titik demi titik. Lebih lanjut,

$\|f\|_{D}=\inf \left\{\left\|\sum_{n=0}^{\infty}\left|f_{n}\right|\right\|_{\infty}:\left\{f_{n}\right\}_{n=0}^{\infty} \subset C(K)\right.$ dan $\sup _{x \in K} \sum_{n=0}^{\infty}\left|f_{n}(x)\right|<\infty$ sehingga $\sum_{n=0}^{\infty} f_{n}=f$ titik demi titik $\}$.

Bukti : (Syarat perlu). Diketahui $f \in D(K)$, maka terdapat fungsi-fungsi semikontinu bawah terbatas $u, v \geq 0$ pada $K$, sehingga $f=u-v$. Karena $u$ fungsi semikontinu bawah terbatas, maka terdapat barisan $\left\{\varphi_{n}\right\} \subseteq C(K)$ sehingga $\varphi_{0} \leq \varphi_{1} \leq \varphi_{2} \leq \varphi_{3} \leq \cdots$ dengan $\varphi_{0}=\mathbf{0}$ dan $\left\{\varphi_{n}\right\}$ konvergen titik demi titik ke $u$. Oleh karena itu, diperoleh

$$
\begin{aligned}
u(x)=\lim _{n \rightarrow \infty} \varphi_{n}(x) & =\lim _{n \rightarrow \infty} \sum_{j=1}^{n}\left(\varphi_{j}-\varphi_{j-1}\right)(x) \\
& =\sum_{j=1}^{\infty}\left(\varphi_{j}-\varphi_{j-1}\right)(x),
\end{aligned}
$$

untuk setiap $x \in K$. Selanjutnya, karena $v$ juga fungsi semikontinu bawah terbatas, maka terdapat barisan $\left\{\psi_{n}\right\} \subseteq C(K)$ sehingga $\psi_{0} \leq \psi_{1} \leq \psi_{2} \leq \cdots$ 
dengan $\psi_{0}=\mathbf{0}$ dan $\left\{\psi_{n}\right\}$ konvergen titik demi titik ke $v$. Oleh karena itu, diperoleh

$$
\begin{aligned}
v(x)=\lim _{n \rightarrow \infty} \psi_{n}(x) & =\lim _{n \rightarrow \infty} \sum_{j=1}^{n}\left(\psi_{j}-\psi_{j-1}\right)(x) \\
& =\sum_{j=1}^{\infty}\left(\psi_{j}-\psi_{j-1}\right)(x),
\end{aligned}
$$

untuk setiap $x \in K$. Sehingga untuk sebarang $x \in K$ diperoleh

$$
\begin{aligned}
f(x) & =u(x)-v(x) \\
& =\sum_{j=1}^{\infty}\left(\varphi_{j}-\varphi_{j-1}\right)(x)-\sum_{j=1}^{\infty}\left(\psi_{j}-\psi_{j-1}\right)(x) \\
& =\sum_{j=1}^{\infty}\left(\varphi_{j}-\varphi_{j-1}-\psi_{j}+\psi_{j-1}\right)(x) .
\end{aligned}
$$

Selanjutnya, namakan $f_{j}=\varphi_{j}-\varphi_{j-1}-\psi_{j}+\psi_{j-1}$, untuk setiap $j \in \boldsymbol{N}$ dengan $f_{0}=\mathbf{0}$, sehingga diperoleh barisan $\left\{f_{n}\right\} \subseteq \mathrm{C}(K)$. Oleh karena itu, $f(x)=\sum_{n=1}^{\infty} f_{n}(x)$, untuk setiap $x \in K$. Dilain pihak, karena $u$ dan $v$ terbatas, maka terdapat $M_{1}, M_{2}>0$ sehingga $|u(x)| \leq M_{1}$ dan $|v(x)| \leq M_{2}$, untuk setiap $x \in K$. Akibatnya, untuk sembarang $x \in K$ berlaku

$$
\sum_{n=1}^{\infty}\left|f_{n}(x)\right|=\sum_{n=1}^{\infty}\left|\left(\varphi_{n}-\varphi_{n-1}-\psi_{n}+\psi_{n-1}\right)(x)\right| \leq M_{1}+M_{2} .
$$

Karena berlaku untuk sebarang $x \in K$, maka diperoleh $\sup _{x \in K} \sum_{n=1}^{\infty}\left|f_{n}(x)\right|<\infty$. Dengan kata lain, ada barisan $\left\{f_{n}\right\} \subseteq C(K)$ dan $\sup _{x \in K} \sum_{n}\left|f_{n}(x)\right|<\infty$ sehingga $\sum_{n} f_{n}=f$ titik demi titik. Oleh karena itu, diperoleh

$\|f\|_{D} \geq \inf \left\{\left\|\sum_{n=0}^{\infty}\left|f_{n}\right|\right\|_{\infty}:\left\{f_{n}\right\}_{n=0}^{\infty} \subset C(K)\right.$ dan $\sup _{x \in K} \sum_{n=0}^{\infty}\left|f_{n}(x)\right|<\infty$, sehingga $\sum_{n=0}^{\infty} f_{n}=f$ titik demi titik\}.

(Syarat cukup). Diketahui barisan $\left\{f_{n}\right\} \subseteq C(K)$ dan $\sup _{x \in K} \sum_{n=0}^{\infty}\left|f_{n}(x)\right|<\infty$ sehingga $\sum_{n=0}^{\infty} f_{n}=f$ titik demi titik. Untuk sembarang $x \in K$, berlaku

$$
\begin{aligned}
f(x)=\sum_{n=1}^{\infty} f_{n}(x) & =\lim _{k \rightarrow \infty} \sum_{n=1}^{k} f_{n}(x) \\
& =\lim _{k \rightarrow \infty} \sum_{n=1}^{k}\left(f_{n}{ }^{+}-f_{n}{ }^{-}\right)(x) \\
& =\lim _{k \rightarrow \infty} \sum_{n=1}^{k}\left(f_{n}{ }^{+}(x)-f_{n}{ }^{-}(x)\right) \\
& =\lim _{k \rightarrow \infty} \sum_{n=1}^{k}\left(f_{n}{ }^{+}\right)(x)-\lim _{k \rightarrow \infty} \sum_{n=1}^{k}\left(f_{n}{ }^{-}\right)(x) \\
& =\sum_{n=1}^{\infty}\left(f_{n}{ }^{+}\right)(x)-\sum_{n=1}^{\infty}\left(f_{n}{ }^{-}\right)(x) .
\end{aligned}
$$


Selanjutnya, namakan $u=\sum_{n=1}^{\infty}\left(f_{n}{ }^{+}\right)$dan $v=\sum_{n=1}^{\infty}\left(f_{n}{ }^{-}\right)$. Karena $f_{n}{ }^{+}, f_{n}{ }^{-} \geq 0$ maka diperoleh $u, v \geq 0$.

Diperhatikan bahwa $\sum_{n=1}^{k}\left(f_{n}\right)^{+}(x) \leq \sum_{n=1}^{k+1}\left(f_{n}\right)^{+}(x)$ untuk setiap $x \in K$, dan $\lim _{k \rightarrow \infty} \sum_{n=1}^{k}\left(f_{n}\right)^{+}(x)=\sum_{n=1}^{\infty}\left(f_{n}\right)^{+}(x)$. Akibatnya, $u$ merupakan fungsi semikontinu bawah terbatas pada $K$. Dengan cara yang sama, diperoleh $v$ merupakan fungsi semikontinu bawah terbatas pada $K$. Oleh karena itu, terdapat fungsi-fungsi semikontinu bawah terbatas $u, v \geq 0$ pada $K$, sehingga $f=u-v$. Dengan kata lain, $f \in D(K)$. Akibatnya, diperoleh $\|f\|_{D} \leq \inf \left\{\left\|\sum_{n=0}^{\infty}\left|f_{n}\right|\right\|_{\infty}:\left\{f_{n}\right\}_{n=0}^{\infty} \subset C(K)\right.$ dan $\sup _{\mathrm{x} \in \mathrm{K}} \sum_{n=0}^{\infty}\left|f_{n}(x)\right|<\infty$, sehingga $\sum_{n=0}^{\infty} f_{n}=f$ titik demi titik\}.

Teorema 2.8 Fungsi $f \in D(K)$ jika dan hanya jika terdapat barisan $\left\{f_{n}\right\}$ di $C(K)$ dan $\mathrm{C}<\infty$, sehingga $\left\{f_{n}\right\}$ konvergen titik demi titik ke $f$ dengan $f_{0}=\mathbf{0}$ dan $\sum_{n=0}^{\infty}\left|f_{n+1}(x)-f_{n}(x)\right| \leq \mathrm{C}$ untuk setiap $x \in K$. Lebih lanjut, $\|f\|_{D}=\inf \left\{\mathrm{C}:\left\{f_{n}\right\} \subseteq C(K), f_{0}=\mathbf{0} \operatorname{dan} \sum_{n=0}^{\infty}\left|f_{n+1}(x)-f_{n}(x)\right| \leq C, \forall x \in K\right.$ sehing $a\left\{f_{n}\right\}$ konvergen titik demi titik ke $\left.f\right\}$.

Bukti : (Syarat perlu). Diketahui $f \in D(K)$ maka menurut Teorema 2.7, terdapat barisan $\left\{g_{n}\right\} \subseteq C(K)$, sehingga $\sum_{n} g_{n}=f$ titik demi titik dan $\sup _{x \in K} \sum_{n}\left|g_{n}(x)\right|<\infty$. Namakan $\mathrm{C}=\sup _{x \in K} \sum_{n}\left|g_{n}(x)\right|$, dan untuk setiap $n \in \boldsymbol{N}$ dibentuk $f_{n}=\sum_{i=1}^{n} g_{i}$ dengan $f_{0}=\mathbf{0}$, maka diperoleh barisan $\left\{f_{n}\right\}$ di $C(K)$ dan $\left\{f_{n}\right\}$ konvergen titik demi titik ke $f$. Untuk sembarang $x \in K$ diperoleh

$$
\begin{aligned}
\sum_{n=0}^{\infty}\left|f_{n+1}(x)-f_{n}(x)\right| & =\sum_{n=0}^{\infty}\left|\sum_{i=1}^{n+1} g_{i}(x)-\sum_{i=1}^{n} g_{i}(x)\right| \\
& =\sum_{n=0}^{\infty}\left|g_{n+1}(x)\right| \leq \mathrm{C} .
\end{aligned}
$$

Dengan kata lain, terdapat barisan $\left\{f_{n}\right\} \subseteq C(K)$ dan $\mathrm{C}<\infty$, sehingga $\left\{f_{n}\right\}$ konvergen titik demi titik ke $f$ dengan $f_{0}=\mathbf{0}$ dan $\sum_{n=0}^{\infty}\left|f_{n+1}(x)-f_{n}(x)\right| \leq \mathrm{C}$ untuk setiap $x \in K$. Oleh karena itu, diperoleh $\|f\|_{D} \geq \inf \left\{C:\left\{f_{n}\right\} \subseteq C(K), f_{0}=\mathbf{0}\right.$ dan $\sum_{n=0}^{\infty}\left|f_{n+1}(x)-f_{n}(x)\right| \leq C, \forall x \in K$ sehingga $\left\{f_{n}\right\}$ konvergen titik demi titik ke $\left.f\right\}$. 
(Syarat cukup). Untuk setiap $n \in \boldsymbol{N}$, dibentuk $g_{n}=f_{n+1}-f_{n}$ dengan $g_{0}=\mathbf{0}$. Akibatnya, diperoleh barisan $\left\{g_{n}\right\} \subseteq C(K)$, dan $\sum_{n=0}^{\infty} g_{n}=f$ titik demi titik. Selanjutnya, untuk sebarang $x \in K$, diperoleh

$$
\sum_{n=0}^{\infty}\left|g_{n}(x)\right|=\sum_{n=0}^{\infty}\left|f_{n+1}(x)-f_{n}(x)\right| \leq \mathrm{C}<\infty .
$$

Karena berlaku untuk sembarang $x \in K$, maka diperoleh $\sup _{x \in K} \sum_{n}\left|g_{n}(x)\right|<\infty$. Dengan kata lain, terbukti $f \in D(K)$. Oleh karena itu, diperoleh $\|f\|_{D} \leq \inf \left\{C:\left\{f_{n}\right\} \subseteq C(K), f_{0}=\mathbf{0}\right.$ dan $\sum_{n=0}^{\infty}\left|f_{n+1}(x)-f_{n}(x)\right| \leq C, \forall x \in K$ sehingga $\left\{f_{n}\right\}$ konvergen titik demi titik ke $\left.f\right\}$.

Telah dibuktikan bahwa $\left(D(K),\|.\|_{D}\right)$ merupakan ruang bernorma, selanjutnya tinggal ditunjukkan bahwa $D(K)$ lengkap.

Teorema 2.9 Diberikan ruang metrik separabel $K, D(K)$ merupakan ruang Banach.

Bukti : Berdasarkan Teorema 2.6, $\left(D(K),\|.\|_{D}\right)$ merupakan ruang bernorma, selanjutnya akan dibuktikan $D(K)$ lengkap. Diambil sebarang barisan Cauchy $\left\{f_{n}\right\} \subseteq D(K)$. Oleh karena itu, dapat diasumsikan $\left\|f_{n+1}-f_{n}\right\|_{D}<\frac{1}{2^{n}}$, untuk setiap $n \in \boldsymbol{N}$. Karena $f_{n+1}-f_{n} \in D(K)$, maka untuk setiap $n \in \boldsymbol{N}$ terdapat barisan $\left\{\varphi_{m}^{n}\right\}_{m=1}^{\infty}$ di $C(K)$, sehingga $\left\{\varphi_{m}^{n}\right\}_{m=1}^{\infty}$ konvergen titik demi titik ke $f_{n+1}-f_{n}$ dan memenuhi

$$
\sum_{m=0}^{\infty}\left|\varphi_{m+1}^{n}(x)-\varphi_{m}^{n}(x)\right| \leq \frac{1}{2^{n}}, \text { untuk setiap } x \in K .
$$

Karena $\left\{f_{n}\right\}$ barisan Cauchy di $D(K)$, maka diperoleh $\left\|f_{m}-f_{n}\right\|_{\infty} \rightarrow 0$, untuk $n, m \rightarrow \infty$. Oleh karena itu, untuk setiap $x \in K$ diperoleh $\left\{f_{n}(x)\right\}$ barisan Cauchy di R. Karena $\mathbf{R}$ lengkap, maka untuk setiap $x \in K$, terdapat $f(x) \in \boldsymbol{R}$ sehingga $\left\{f_{n}(x)\right\}$ konvergen ke $f(x)$. Akibatnya diperoleh $\left\|f_{n}-f\right\|_{\infty} \rightarrow 0$.

Diambil sembarang $n_{0} \in \boldsymbol{N}$. Dibentuk $g_{n}=f_{n+1}-f_{n}$, untuk setiap $n \in \boldsymbol{N}$ dan $\psi_{n}=\left(\varphi_{n}^{n_{0}}+\cdots+\varphi_{n}^{l}\right)+\left(\varphi_{n+1}^{l+1}-\varphi_{n}^{l+1}\right)+\cdots+\left(\varphi_{n+1}^{n}-\varphi_{n}^{n}\right)$, untuk setiap $l, n \in N$ dengan $n_{0} \leq l<n$. Oleh karena itu didapat barisan $\left\{\psi_{n}\right\} \subseteq C(K)$ dan berlaku 


$$
\begin{aligned}
\sum_{n=n_{0}}^{\infty} g_{n} & =\lim _{k \rightarrow \infty} \sum_{n=n_{0}}^{k} g_{n} \\
& =\lim _{k \rightarrow \infty} \sum_{n=n_{0}}^{k}\left(f_{n+1}-f_{n}\right) \\
& =\lim _{k \rightarrow \infty}\left(f_{k+1}-f_{n_{0}}\right)=f-f_{n_{0}} .
\end{aligned}
$$

Selanjutnya, akan dibuktikan $f-f_{n_{0}} \in D(K)$. Untuk setiap $l, n \in \boldsymbol{N}$ dengan $n_{0} \leq l<n$, diperoleh

$$
\begin{aligned}
\left\|\psi_{n}-\left(\varphi_{n}^{n_{0}}+\cdots+\varphi_{n}^{l}\right)\right\|_{\infty} & =\left\|\left(\varphi_{n+1}^{l+1}-\varphi_{n}^{l+1}\right)+\cdots+\left(\varphi_{n+1}^{n}-\varphi_{n}^{n}\right)\right\|_{\infty} \\
& \leq \sum_{i=l+1}^{n} \frac{1}{2^{i}} \leq \frac{1}{2^{l}} .
\end{aligned}
$$

Oleh karena itu, apabila $n \rightarrow \infty$ maka untuk setiap $x \in K$ dan $l \geq n_{0}$, diperoleh

$$
\lim _{n \rightarrow \infty}\left|\psi_{n}(x)-\left(\varphi_{n}^{n_{0}}+\cdots+\varphi_{n}^{l}\right)(x)\right| \leq \frac{1}{2^{l}} .
$$

Akibatnya, diperoleh

$$
g_{n_{0}}(x)+\cdots+g_{l}(x)-\frac{1}{2^{l}} \leq \lim _{n \rightarrow \infty} \psi_{n}(x) \leq g_{n_{0}}(x)+\cdots+g_{l}(x)+\frac{1}{2^{l}} .
$$

Selanjutnya, apabila $l \rightarrow \infty$, maka diperoleh $\left\{\psi_{n}\right\}$ konvergen titik demi titik ke $f-f_{n_{0}}$. Disisi lain, diperoleh

$$
\begin{aligned}
\sum_{n=0}^{\infty}\left|\psi_{n+1}(x)-\psi_{n}(x)\right| \leq & \sum_{n=0}^{\infty}\left|\varphi_{n+1}^{n_{0}}(x)-\varphi_{n}^{n_{0}}(x)\right|+\cdots+ \\
& \sum_{n=0}^{\infty}\left|\varphi_{n+1}^{l}(x)-\varphi_{n}^{l}(x)\right|+ \\
& \sum_{n=0}^{\infty}\left|\varphi_{n+1}^{l+1}(x)-\varphi_{n}^{l+1}(x)\right|+\cdots+ \\
& \sum_{n=0}^{\infty}\left|\varphi_{n+1}^{n}(x)-\varphi_{n}^{n}(x)\right|+ \\
& \sum_{n=0}^{\infty}\left|\varphi_{n+2}^{l+1}(x)-\varphi_{n+1}^{l+1}(x)\right| \\
& +\cdots+\sum_{n=0}^{\infty}\left|\varphi_{n+2}^{n+1}(x)-\varphi_{n+1}^{n+1}(x)\right| \\
\leq & \sum_{i=n_{0}}^{n+1} \frac{1}{2^{i}} \leq \frac{1}{2},
\end{aligned}
$$

untuk setiap $x \in K$. Dengan demikian terdapat barisan $\left\{\psi_{n}\right\} \subseteq C(K)$ yang konvergen titik demi titik ke $f-f_{n_{0}}$, dan $\sum_{n=0}^{\infty}\left|\psi_{n+1}(x)-\psi_{n}(x)\right| \leq \frac{1}{2}$. Dengan kata lain benar bahwa $f-f_{n_{0}} \in D(K)$. Karena $D(K)$ ruang linear, maka diperoleh $f \in D(K)$. Selanjutnya, berdasarkan asumsi diawal pembuktian, maka diperoleh 


$$
\begin{aligned}
\left\|f-f_{n_{0}}\right\|_{D} & =\left\|\sum_{n=n_{0}}^{\infty} g_{n}\right\|_{D} \\
& =\left\|\sum_{n=n_{0}}^{\infty} f_{n+1}-f_{n}\right\|_{D} \\
& \leq \sum_{n=n_{0}}^{\infty}\left\|f_{n+1}-f_{n}\right\|_{D} \\
& \leq \sum_{n=n_{0}}^{\infty} \frac{1}{2^{n}} \leq \frac{1}{2^{n-1}-1}, \text { untuk setiap } n_{0} \in \boldsymbol{N} .
\end{aligned}
$$

Karena berlaku untuk sembarang $n_{0} \in \boldsymbol{N}$, maka diperoleh barisan $\left\{f_{n}\right\}$ konvergen ke $f$. Jadi, terbukti $D(K)$ ruang Banach.

\section{KESIMPULAN DAN SARAN}

Berdasarkan hasil dan pembahasan pada bagian 2 (dua), dapat disimpulkan bahwa dalam membuktikan sifat ruang Banach pada $D(K)$ dibutuhkan beberapa sifat terkait dengan definisi norma pada $D(K)$. Berdasarkan hasil ini, penulis menyarankan agar dapat dibuktikan sifat aljabar pada $D(K)$ dan sifat-sifat $D(K)$ lebih lanjut.

\section{UCAPAN TERIMA KASIH}

Terima kasih penulis ucapkan kepada bapak Atok Zulijanto atas bimbingannya selama ini.

\section{DAFTAR PUSTAKA}

A.S. Kechris, A.S. dan Louveau.A, (1990) A classification of Baire Class 1 Functions, Trans. Amer. Math. Soc. 318 209-236.

Farmaki, V., (1996) On Baire-1/4 Functions, Trans. Amer. Math. Soc, 348, 10

Haydon, R., Odell, E. dan Rosenthal, H.P., (1991) On Certain Classes of Baire-1 Functions with Applications to Banach Space Theory, Lecture Notes in Math., 1470, Springer, New York.

McShane, E.J., (1944) Integration, Princeton University Press, Princeton.

Rosenthal, H.P., (1994) A Characterization of Banach Spaces Containing C0, J. Amer. Math. Soc, 7, 3, 707-748.

Rosenthal, H.P., (1994) Differences of Bounded Semi-Continuous Functions I, http://www.arxiv.org/abs/math/9406217, 20 Juni 1994, diakses pada tanggal 27 Agustus 2009. 